\title{
COMPARISONS OF WELDED STEEL STRUCTURES DESIGNED FOR MINIMUM COST
}

\author{
JÓZSEF FARKAS \\ Institute of Logistics, University of Miskolc \\ H-3515 Miskolc, Miskolc-Egyetemváros, Hungary \\ altfar@uni-miskolc.hu
}

[Received: February 2, 2016. Accepted: April 10, 2016]

\begin{abstract}
Cost is an important characteristic of welded structures, since welding is an expensive fabrication technology. The developed cost calculation method enables designers to predict the cost of material, assembly, welding and painting costs in the design stage. Cost comparison can select the most economical structural version. Since only optimized versions can be compared to each other realistically, a minimum cost design procedure should be performed for each version.

In the present study cost comparisons are discussed for the following welded structures: (a) a cantilever column constructed from stringer-stiffened circular cylindrical shell as well as from square box section with stiffened or cellular plates, (b) a stiffened or cellular plate supported at four corners, (c) a wind turbine tower constructed as a ring-stiffened slightly conical circular shell or as a tubular truss, (d) a ring-stiffened slightly conical shell with equidistant or non-equidistant stiffening.
\end{abstract}

Keywords: Structural optimization, welded steel structures, cost calculations, stiffened and cellular plates, conical shells

\section{INTRODUCTION}

Comparisons of main structural characteristics help designers to select the best versions. The large selection of structural types made from welded plates or profiles enables designers to construct load-carrying engineering structures, which fulfil not only the constraints on safety and fabrication, but also are economic. Economy is an important requirement, since welding is an expensive fabrication technology.

In order to characterize the economy of structural versions we have developed a cost calculation method mainly adaptable for welded steel structures in the design phase. Based on this cost function we have worked out a number of optimization problems for different structural types. Realistic numerical models have been used to show how to construct safe, fit for production and economic welded structures.

We have used cost comparisons in many optimization problems to find the minimum cost version. In the present paper the results of these minimum cost design studies are collected to make cost comparisons useful for designers in selecting the 
most suitable and competitive structural versions. Since only optimized versions can be realistic compared to each other, each version is optimized for minimum cost.

Since the detailed studies of these problems have already been published, only the main characteristics, results and discussion of the cost differences are presented here.

\section{The cost Calculation method}

The general formula for the welding cost is as follows $[1-4$ :

$$
K_{w}=k_{w}\left(C_{1} \Theta \sqrt{\kappa \rho V}+1.3 \sum_{i} C_{w i} a_{w i}^{n} C_{p i} L_{w i}\right)
$$

where $k_{w}[\$ / \mathrm{min}]$ is the welding cost factor, $C_{1}$ is the factor for the assembly usually taken as $C_{1}=1 \mathrm{~min} / \mathrm{kg}^{0.5}, \Theta$ is the factor expressing the complexity of assembly, the first member calculates the time of the assembly, $\kappa$ is the number of structural parts to be assembled, $V$ is the volume, $\rho V$ is the mass of the assembled structure, the second member estimates the time of welding, $C_{w}$ and $n$ are the constants given for the specified welding technology and weld type.

Furthermore $C_{p i}$ is the factor for the welding position (download 1, vertical 2, overhead 3$), L_{w}$ is the weld length, the multiplier 1.3 takes into account the additional welding times (deslagging, chipping, changing the electrode).

Material cost is calculated as

$$
K_{m}=k_{m} \rho V, \quad k_{m}=1.0 \$ / \mathrm{kg}
$$

where $V$ is the volume of a structural part. The painting cost is

$$
K_{P}=k_{P} S, \quad k_{P}=28.8 \times 10^{-6} \$ / \mathrm{mm}^{2}
$$

in which $S$ is the surface to be painted.

\section{A COLUMN IN COMPRESSION AND BENDING WITH A CONSTRAINT ON TOP SWAY}

This structural component is used in buildings and piers of highways. Since during the large earthquake in Kobe in 1995 many highway piers were destroyed by too large horizontal seismic forces, Japanese researchers have made great efforts to work out advanced seismic-resistant structural versions. Although our studies do not contain earthquake loads, our results can be applied in the design of seismic-resistant structural versions.

We have optimized three structural versions using the same column height, loads, constraints and similar cost calculations.

3.1. Column constructed as a stringer-stiffened circular cylindrical shell. The investigated structure is a supporting column loaded by an axial and horizontal force (Figure 1). The horizontal displacement of the top is limited for serviceability of the supported structure. Both the stiffened and unstiffened shell versions are optimized and their cost is compared to each other. In the stiffened shell outside 
longitudinal stiffeners of halved rolled $I$-section (UB) are used. The cost function is formulated according to the fabrication sequence.

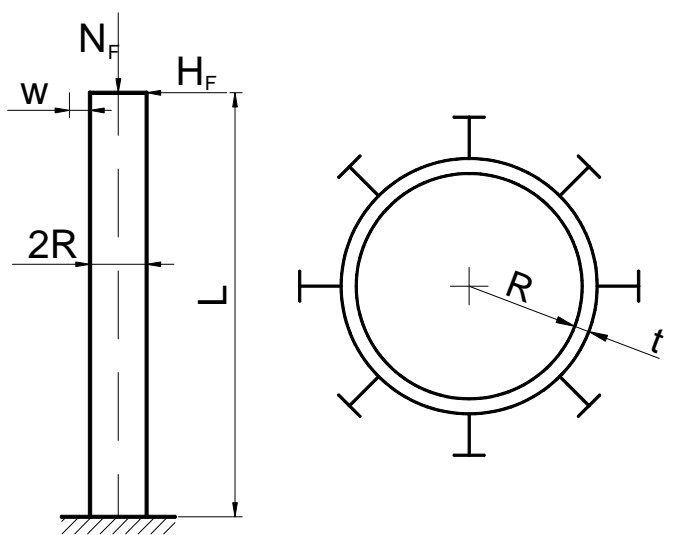

Figure 1. A cantilever column and its cross-section of stringerstiffened circular cylindrical shell

Numerical data: The vertical load $N_{F}=34000 \mathrm{kN}$, the horizontal force $H_{F}=$ $0.1 N_{F}$, the yield stress $f_{y}=355 \mathrm{MPa}, R=1850 \mathrm{~mm}, L=15 \mathrm{~m}$. The discrete values of $h$ and the nominal size of $I$-beam (UB)(in the parenthesis) are as follows according to the ARCELOR catalog: 152.4 (152), 177.8 (178), 203.2 (203), 257.2 (254), 308.7 (305), 353.4 (356), 403.2 (406), 454.6 (457), 533.1 (533), 607.6 (610), 683.5 (686), 762.2 (762), 840.7 (838), 910.4 (914), 1008.1 (1016) mm. The main dimensions of some UB profiles are given in Table 3 . Cost $K$ is given in USD (\$) throughout the paper.

Table 1. Results of the optimization for stiffened and unstiffened shell. The positive cost difference means savings due to stiffening. Stiffener height $(h)$ and shell thickness $(t)$ in $\mathrm{mm}, \operatorname{cost}(K)$ in $\$$

\begin{tabular}{|ccccc|cc|c|}
\hline \multicolumn{5}{|c|}{ Stiffened } & \multicolumn{2}{c|}{ Unstiffened } & $\begin{array}{c}\text { Cost } \\
\text { difference }\end{array}$ \\
\hline$\phi$ & $h$ & $n$ & $t$ & $K$ & $t$ & $K$ & \\
\hline 400 & 203 & 5 & 24 & 56,310 & 22 & 49480 & -14 \\
500 & 610 & 5 & 22 & 56,082 & 22 & 49,480 & -13 \\
600 & 406 & 5 & 23 & 55,760 & 25 & 55,800 & 0 \\
700 & 686 & 14 & 16 & 57,751 & 29 & 64,440 & 12 \\
800 & 914 & 10 & 16 & 62,294 & 33 & 73,370 & 18 \\
900 & 914 & 15 & 12 & 66,545 & 37 & 82,580 & 24 \\
1000 & 914 & 18 & 11 & 70,571 & 41 & 92,100 & 30 \\
\hline
\end{tabular}

Constraints on shell buckling (unstiffened curved panel buckling) and stringer panel buckling are formulated according to DNV design rules. Horizontal displacement on the top is limited to $L / \phi=L / 400-L / 1000$. 
The optimization is performed using the Particle Swarm mathematical algorithm [4]. The results are summarized in Table 1.

The buckling stress constraint is active when the allowable horizontal displacement is $\mathrm{L} / 400-\mathrm{L} / 500$ and for these cases the unstiffened shell is cheaper than the stiffened one. On the other hand, for $L / 700-L / 1000$ the displacement constraint is active and the stringer-stiffened shell is cheaper than the unstiffened one. The cost savings achieved by stiffening are $12-30 \%$.

\subsection{Columns of square box section constructed from stiffened or cellular} plates. A cantilever stub column of square box section is optimized. The column is subject to compression and bending and is constructed from four equal orthogonally stiffened and cellular side plates. The thickness and width of side plates as well as the dimensions and numbers of longitudinal stiffeners are calculated to fulfill the constraints and minimize the cost function.

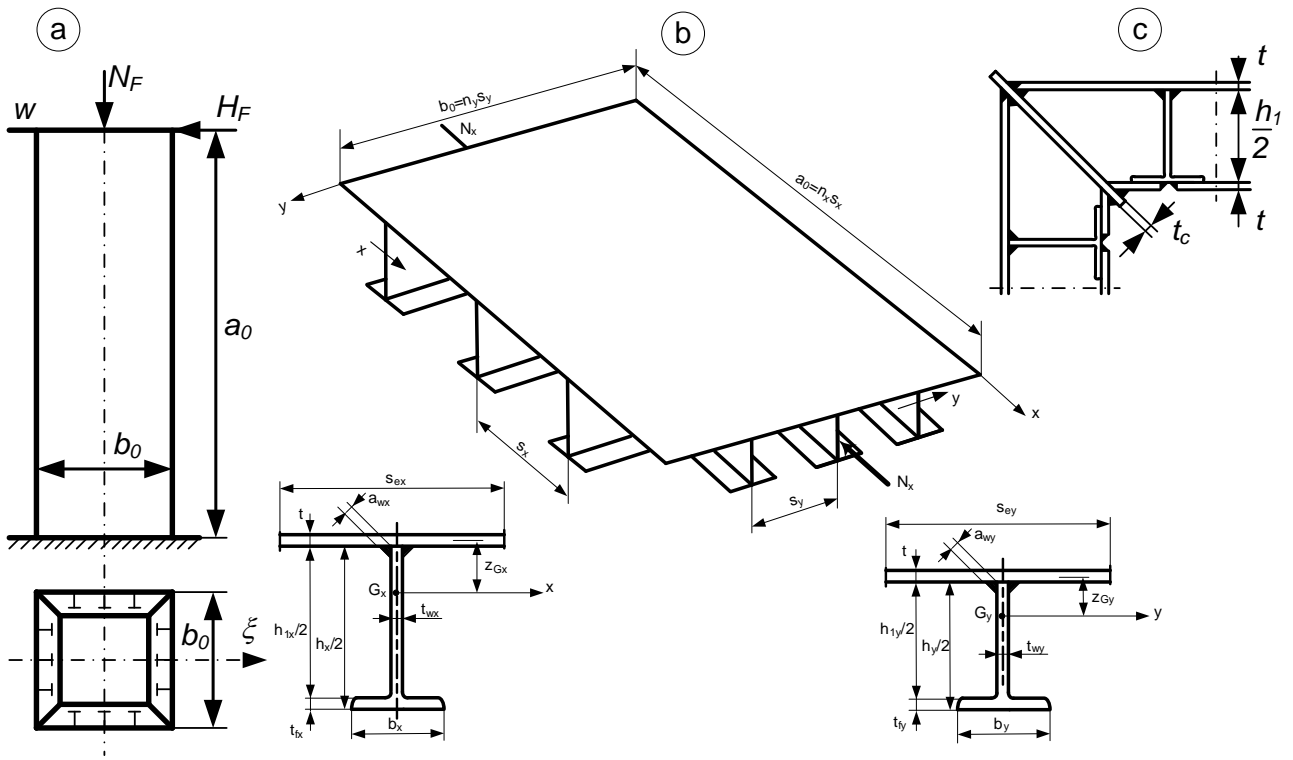

Figure 2. A cantilever column can be constructed of stiffened or cellular plates. (a) Main dimensions and loads, (b) orthogonally stiffened plate, (c) corner construction with cellular plates

The constraints on overall buckling are formulated according to the Det Norske Veritas design rules [5]. The horizontal displacement of the column top is limited. The minimum distance between stiffeners is prescribed to ease the welding of stiffeners to the base plates.

Halved rolled $I$-profile stiffeners are used. Their height characterizes the whole profile, since the other dimensions can be expressed by height using approximate functions derived from the data of a profile series selected from available sections. 
The cost function is formulated according to the fabrication sequence.

It is possible to compare the costs of structural versions of the column with the same height, loads and constraints on stress and displacement as follows.

(1) The stringer-stiffened circular shell with a radius of $1850 \mathrm{~mm}$ has the minimum cost of $K=70571$ (unstiffened $K=92,100 \$$ ),

(2) The square box structure composed from orthogonally stiffened plates with an optimized width of $b_{0}=4500 \mathrm{~mm}$ has the minimum cost of $K=76,990 \$$ (see 4]),

(3) The cellular box structure loaded by a slightly different compression force $(30000$ instead of $34000 \mathrm{kN})$ with an optimized width of $b_{0}=4700 \mathrm{~mm}$ has the minimum cost of $K=60,430 \$$.

It can be concluded that the cellular box column is the most economic structural version, since cellular plates have much higher torsional stiffness that the plates stiffened on one side.

\section{Stiffened or CELlular SQUARE Plates Supported AT FOUR CORNERS}

4.1. The stiffened square plate. A square plate is investigated subject to uniformly distributed normal static load, supported at four corners, stiffened by a square symmetrical orthogonal grid of ribs. Halved rolled I-section stiffeners are used welded to the base plate by double fillet welds (Figure 3) [4, 6]

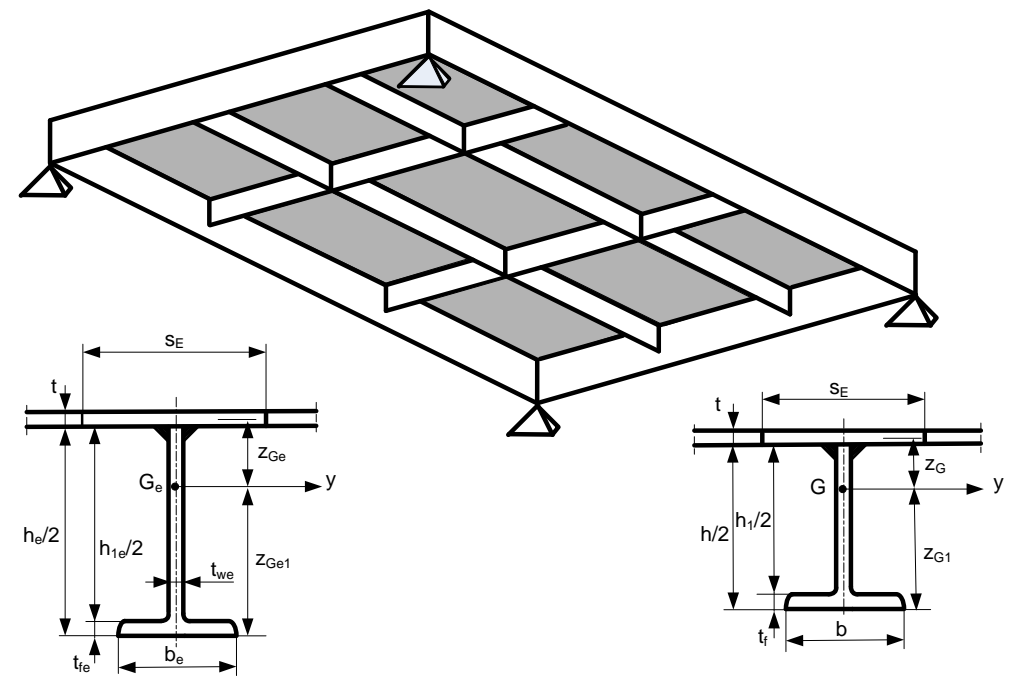

Figure 3. A stiffened square plate supported at four corners. Crosssections of external (a) and internal (b) stiffeners of halved rolled I-section

The bending moments are calculated using the force method for torsionless gridworks with different numbers of stiffeners. Constraints on stress in the base plate 
and in stiffeners as well as on deflection of edge beams and of internal stiffeners are formulated. The cost function includes material, welding and painting costs and is formulated according to the fabrication sequence.

The unknowns are the base plate thickness $(t)$, the heights of edge $\left(h_{e}\right)$ and internal $(h)$ stiffeners and the number of internal stiffeners $(n)$.

Numerical data: Yield stress of steel $f_{y}=355 \mathrm{MPa}, f_{y 1}=f_{y} / 1.1=322$, elastic modulus $E=2.1 \times 10^{5} \mathrm{MPa}$, edge length of the base plate $L=18.0 \mathrm{~m}$, factored load intensity $p_{0}=0.0015 \mathrm{~N} / \mathrm{mm}^{2}$, load intensity considering the self mass

$$
p=p_{0}+\rho_{0} \frac{V}{L^{2}}
$$

where density of steel $\rho=7.85 \times 10^{-6} \mathrm{~kg} / \mathrm{mm}^{3}, \rho_{0}=7.85 \times 10^{-5} \mathrm{~N} / \mathrm{mm}^{3}$, admissible deflection $w_{a d m}=L / 300=60 \mathrm{~mm}$, factor for the complexity of assembly $\Theta=3$, factor for the complexity of painting $\Theta_{F}=3$, cost factors: $k_{m}=1.0 \$ / \mathrm{kg}, k_{w}=1.0$ $\$ / \mathrm{min}, k_{P}=14.4 \times 10^{-6} \$ / \mathrm{mm}^{2}$. The ranges of unknowns: $t=4-40 \mathrm{~mm}, h$ and $h_{e}=152-1008.1 \mathrm{~mm}$.

Results obtained for discrete variables are summarized in Table 2.

Table 2. Results obtained by Particle Swarm Optimization for discrete variables. Dimensions and deflections in $\mathrm{mm}$, stresses in the external fibres for edge and internal stiffeners in MPa, costs $(K)$ in $\$$. The minimum cost is marked by bold letters

\begin{tabular}{|ccccccccccc|}
\hline$n$ & $h_{e}$ & $h$ & $t$ & $\sigma_{e 1}$ & $\sigma_{e}$ & $\sigma_{1}$ & $\sigma$ & $w_{e}$ & $w$ & $K$ \\
\hline 3 & 1016 & 607.6 & 14 & 208 & 310 & 112 & 106 & 36.1 & 47.6 & 118,500 \\
4 & 1016 & 607.6 & 9 & 109 & 286 & 205 & 285 & 51.6 & 51.7 & $\mathbf{1 0 6 , 8 0 0}$ \\
5 & 1008.1 & 762.2 & 12 & 142 & 233 & 301 & 299 & 45.9 & 42.7 & 134,200 \\
\hline
\end{tabular}

4.2. The cellular square plate. Cellular plates can be applied in various structures e.g. in floors and roofs of buildings, in bridges, ships, machine structures, etc. Cellular plates have the following advantages over the plates stiffened on one side: (a) because

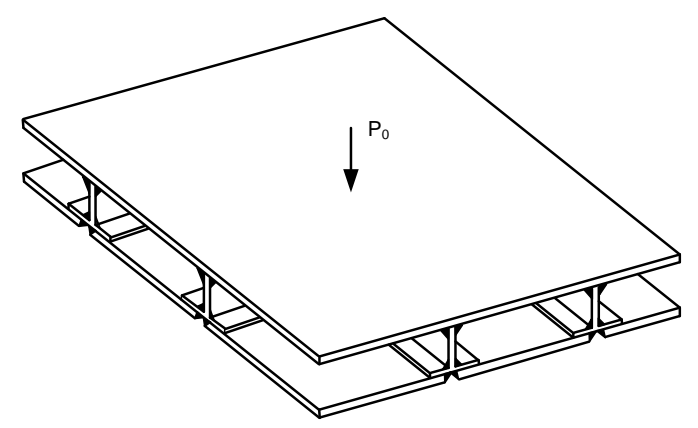

Figure 4. A square cellular plate 
of their large torsional stiffness the plate thickness can be decreased, which results in a decrease in welding cost, (b) their planar surface is more suitable for corrosion protection, (c) their symmetric welds do not cause residual distortion.

In a previous study 7 it was shown that cellular plates can be calculated as isotropic ones and bending moments and deflections can be determined by using classic results of isotropic plates for various load and support types.

In the present study a cellular plate is designed which is supported at four corners and subject to a uniformly distributed normal load.

In order to guarantee a suitable fabrication procedure halved rolled I-section stiffeners are used, their web is welded to the upper base plate by double fillet welds and the bottom base plate parts are welded to the stiffener flanges also by fillet welds (Figure 4).

Structural characteristics to be changed (variables):

- number of stiffeners in one direction (square symmetry) $n$,

- thicknesses of the upper and bottom base plates $t_{1}$ and $t_{2}$,

- height of the rolled $I$-section stiffener $h$.

Other dimensions of UB profiles are given in Table 3 Note that for these dimensions approximate formulae can be applied as well.

Available series of rolled $I$-sections: UB profiles selected according to the ARCELOR catalog 8 (necessary for the optimization).

Table 3. Selected UB profiles according to the ARCELOR catalogue

\begin{tabular}{|ccccc|}
\hline UB profile & $h$ & $b$ & $t_{w}$ & $t_{f}$ \\
\hline $610 \times 229 \times 113$ & 607.6 & 228.2 & 11.1 & 17.3 \\
$686 \times 254 \times 140$ & 683.5 & 253.7 & 12.4 & 19.0 \\
$762 \times 267 \times 173$ & 762.2 & 266.7 & 14.3 & 21.6 \\
$838 \times 292 \times 194$ & 840.7 & 292.4 & 14.7 & 21.7 \\
$914 \times 305 \times 224$ & 910.4 & 304.1 & 15.9 & 23.9 \\
$1016 \times 305 \times 349$ & 1008.1 & 302.0 & 21.1 & 40.0 \\
\hline
\end{tabular}

Numerical data: Plate edge length: $L=18 \mathrm{~m}$, factored load intensity $p_{0}=150 \mathrm{~kg} / \mathrm{m}^{2}=$ $0.0015 \mathrm{~N} / \mathrm{mm}^{2}$, yield stress of steel $f_{y}=355 \mathrm{MPa}$, elastic modulus $E=2.1 \times 10^{5}$ $\mathrm{MPa}$, Poisson ratio $\nu=0.3$, steel density $\rho=7.85 \times 10^{-6} \mathrm{~kg} / \mathrm{mm}^{3}, \rho_{0}=7.85 \times 10^{-5}$ $\mathrm{N} / \mathrm{mm}^{3}$.

Optimization and results: In the optimization process the optimum values of variables are sought that fulfil the design and fabrication constraints and minimize the cost function. Calculation shows that the deflection constraint is always active, and the minimum cost corresponds to the minimum value of plate thickness $t_{2}=4 \mathrm{~mm}$. The results are summarized in Table 4.

It can be seen that the cost increases when $h$ decreases, thus it is not necessary to continue with the search. The optimum is marked by bold letters. Each result given in Table 4 satisfies all the constraints. 
Table 4. Optimization results. Allowable deflection is $60 \mathrm{~mm}$. Dimensions and deflections in $\mathrm{mm}$, stresses in $\mathrm{MPa}$

\begin{tabular}{|ccccccc|}
\hline$h$ & $n$ & $t_{1}$ & $t_{2}$ & $\sigma_{2}$ & $w_{\max }$ & $10^{-5} K \$$ \\
\hline 1008.1 & 3 & 8 & 7 & 191 & 57.2 & 1.125 \\
& 4 & 7 & 4 & 122 & 57.2 & 1.071 \\
& $\mathbf{5}$ & $\mathbf{5}$ & $\mathbf{4}$ & $\mathbf{1 6 6}$ & $\mathbf{5 9 . 6}$ & $\mathbf{1 . 0 6 1}$ \\
& 6 & 4 & 4 & 191 & 56.8 & 1.094 \\
910.4 & 3 & 12 & 4 & 65 & 57.6 & 1.158 \\
& 4 & 10 & 4 & 60 & 59.1 & 1.121 \\
& 5 & 9 & 4 & 51 & 56.9 & 1.129 \\
840.7 & 3 & 14 & 4 & 47 & 57.7 & 1.232 \\
& 4 & 12 & 4 & 41 & 58.4 & 1.188 \\
& 5 & 11 & 4 & 34 & 56.0 & 1.191 \\
& 6 & 10 & 4 & 30 & 55.0 & 1.195 \\
& 7 & 9 & 4 & 29 & 55.2 & 1.200 \\
\hline
\end{tabular}

Comparing the two structural versions it can be concluded that the cellular plate is competitive to the plate stiffened on one side, since the costs are nearly the same $(106,800$ compared to $106,100 \$)$ and the cellular construction has some advantages over the stiffened one.

\section{A Wind tURBine tower}

Steel towers for wind turbines can be constructed in various structural versions. Ringstiffened cylindrical shells or tubular trusses are usually applied.

The cost comparison is applied now to two structural versions of a wind turbine tower. The tower is $45 \mathrm{~m}$ high, loaded on the top by a factored vertical force of 950 $\mathrm{kN}$ (self weight of the nacelle), a bending moment of $997 \mathrm{kNm}$ and a horizontal force of $282 \mathrm{kN}$ from the turbine operation. The tower width is limited to $2.5 \mathrm{~m}$ due to the rotating turbine blades of length $27 \mathrm{~m}$.

Both the shell and the truss structure are constructed from 3 parts each of $15 \mathrm{~m}$ length with stepwise increasing widths. The shell parts are designed against shell buckling and panel ring buckling according to the design rules of the Det Norske Veritas [5]. The number of flat ring stiffeners is determined by the designer to avoid larger ovalization of the cylindrical shell. The 3 shell parts are joined by bolted connections.

5.1. The ring-stiffened shell structure. Design constraints on shell buckling and on local buckling of flat ring-stiffeners are formulated according to DNV [5] and API [9] design rules. The wind load acting on the shell tower is calculated according to Eurocode 1 Part 2-4 10]. To avoid shell ovalization a minimum number of 5 and a maximum number of 15 stiffeners is prescribed. In the shell buckling constraint an imperfection factor as proposed by Farkas [3] is used, which expresses the effect of radial shell deformation due to shrinkage of circumferential welds. 


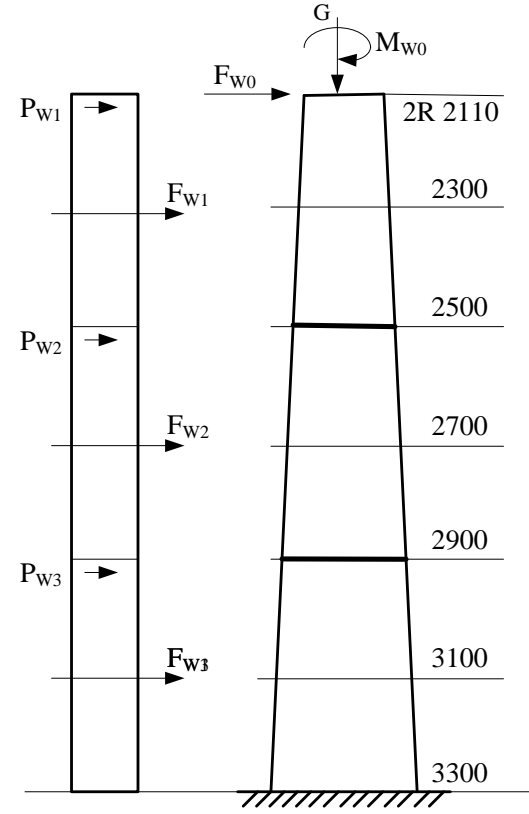

(a)

(b)

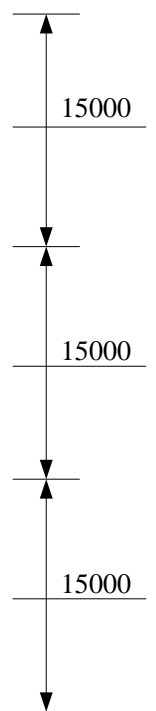

(1)
1496

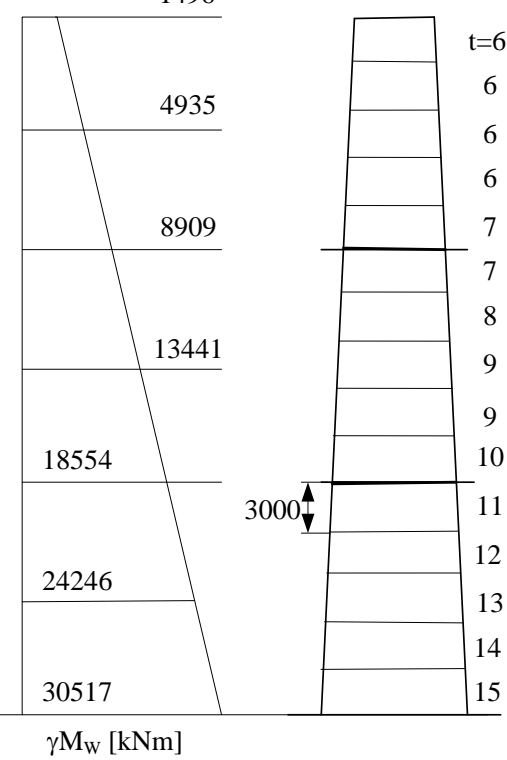

(d)

Figure 5. A wind turbine tower constructed as a ring-stiffened circular slightly conical shell. (a) wind loads, (b) diameters of the shell, (c) bending moments, (d) shell thicknesses

The optimization has been performed using Rosenbrock's search algorithm 1]. The optimal values of the shell thickness $(t)$ for $n=5$, which comply with the design constraints and minimize the cost function, are given in Figure 5d. The minimal masses and costs are summarized in Table 5

Table 5. Summary of masses $(\mathrm{kg})$ and costs $(\$)$

\begin{tabular}{|ccccc|}
\hline Shell part & Mass & Cost without $K_{p}$ & $K_{p}$ & Total $K$ \\
\hline top & 5398 & 12096 & 6440 & 18,536 \\
middle & 9472 & 19772 & 7603 & 27,373 \\
bottom & 15648 & 30941 & 8778 & 39,719 \\
total & 30518 & 62809 & 22821 & 85,628 \\
\hline
\end{tabular}

5.2. The tubular truss structure. The truss is statically determinate. The distance between parallel chords in the upper part of the tower is limited because of the rotating blades (Figure 6).

Thus, in the optimization procedure the inclination angle or the larger constant chord distance and the member dimensions of the lower tower part are sought that minimize the structural volume and fulfill the design constraints. 


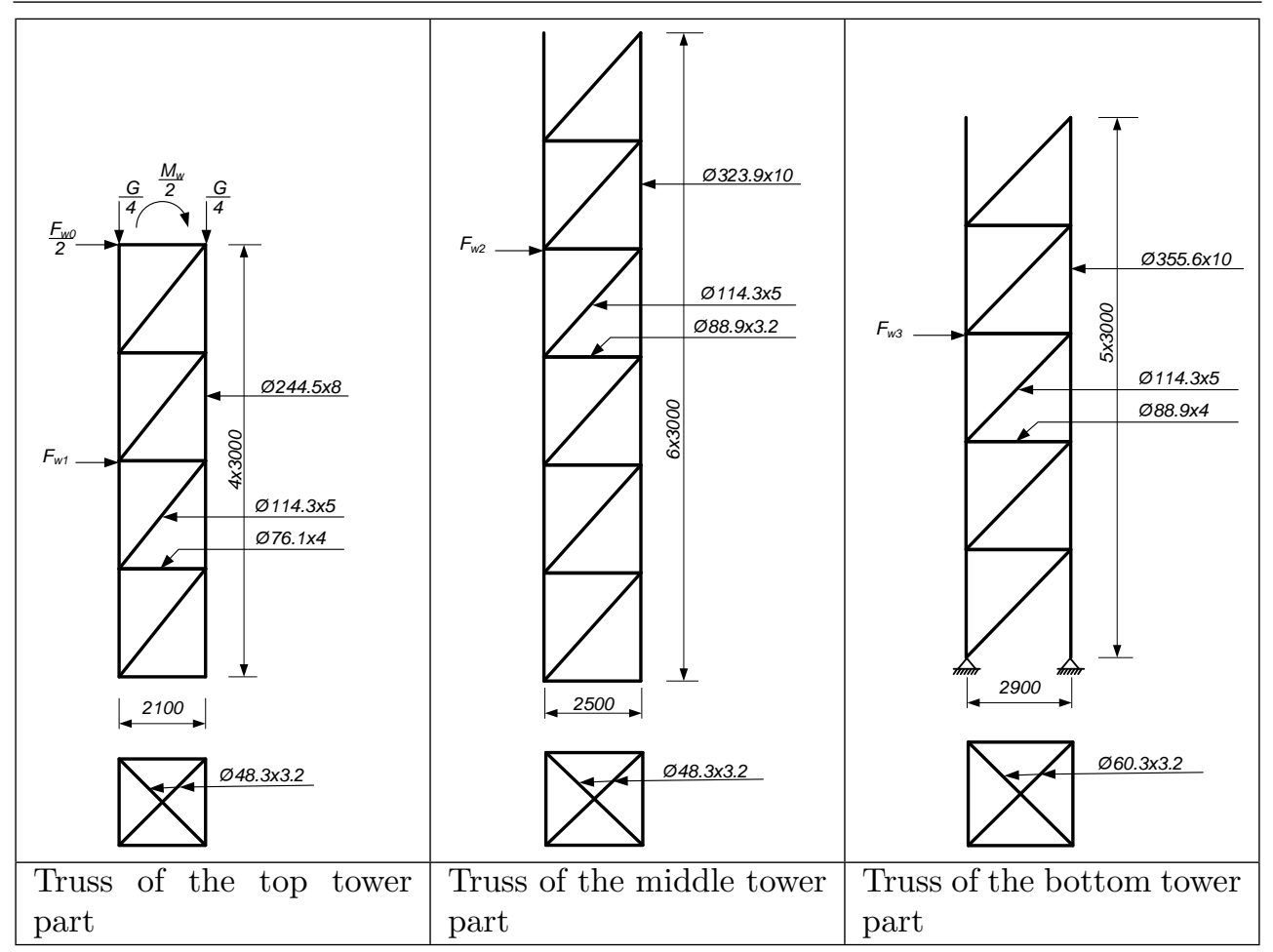

Figure 6. A wind turbine tower constructed as a tubular truss

The constraints relate to the buckling strength of circular hollow section (CHS) members and to the local strength of welded tubular joints. Seismic behavior is not considerred. In the numerical problem the loads from wind acting on the turbine and from the nacelle mass are selected from the literature. With the member forces an iterative suboptimization method is used for the calculation of compression member dimensions.

The cross-section of the truss can be quadratic or triangular. In the case of a triangular cross-section the whole horizontal load should be carried by a truss plane, since the horizontal load direction is variable. Therefore the quadratic cross-section is used. In this case only the half value of the horizontal load is acting on a truss plane.

The tubular truss structure consists of three parts with different but constant width. The four truss planes are stiffened by horizontal diaphragms constructed from two struts.

Both structural versions are checked for eigenfrequency and fatigue [11]. The details of the cost calculation are summarized in Table6, where $G$ - mass, $K_{m}$ - material cost, $K_{C G}-$ cost of cutting and grinding of the tubular member ends, $K_{A}-$ cost of assembly, $K_{w}$ - cost of welding, $K_{P}$ - cost of painting, $K$ - total cost. 
Table 6. Costs in $\$$ of the tubular tower, the surface $A_{P}$ to be painted in $\mathrm{mm}^{2}$

\begin{tabular}{|ccccccccc|}
\hline Part & $G \mathrm{~kg}$ & $K_{m}$ & $K_{C G}$ & $K_{A}$ & $K_{w}$ & $A_{P x} 10^{-6}$ & $K_{P}$ & $K$ \\
\hline Top & 3437 & 4139 & 1936 & 1180 & 2514 & 72.46 & 2087 & 11,856 \\
Middle & 7395 & 9096 & 2867 & 1965 & 3108 & 130.11 & 3747 & 20,783 \\
Bottom & 6701 & 8643 & 2551 & 1629 & 2353 & 116.17 & 3346 & 18,522 \\
\hline Total & 17533 & 21878 & 7354 & 4774 & 7975 & 318.74 & 9180 & 51,161 \\
\hline
\end{tabular}

The comparison of the two structural versions (Tables 5 and 6) shows that the tubular truss has smaller mass (17533 compared to $30518 \mathrm{~kg}$ ), smaller surface to be painted and is much cheaper than the shell structure (51,161 compared to 85,628 \$). This difference is caused by the much lower mass and surface of the tubular truss version.

\section{A Ring-STIFFENED SLIGHTLY CONICAL SHELl LOADED BY EXTERNAL PRESSURE}

Conical shells are applied in numerous structures, e.g. in submarine and offshore structures, aircraft, tubular structures, towers and tanks, etc. Their structural characteristics

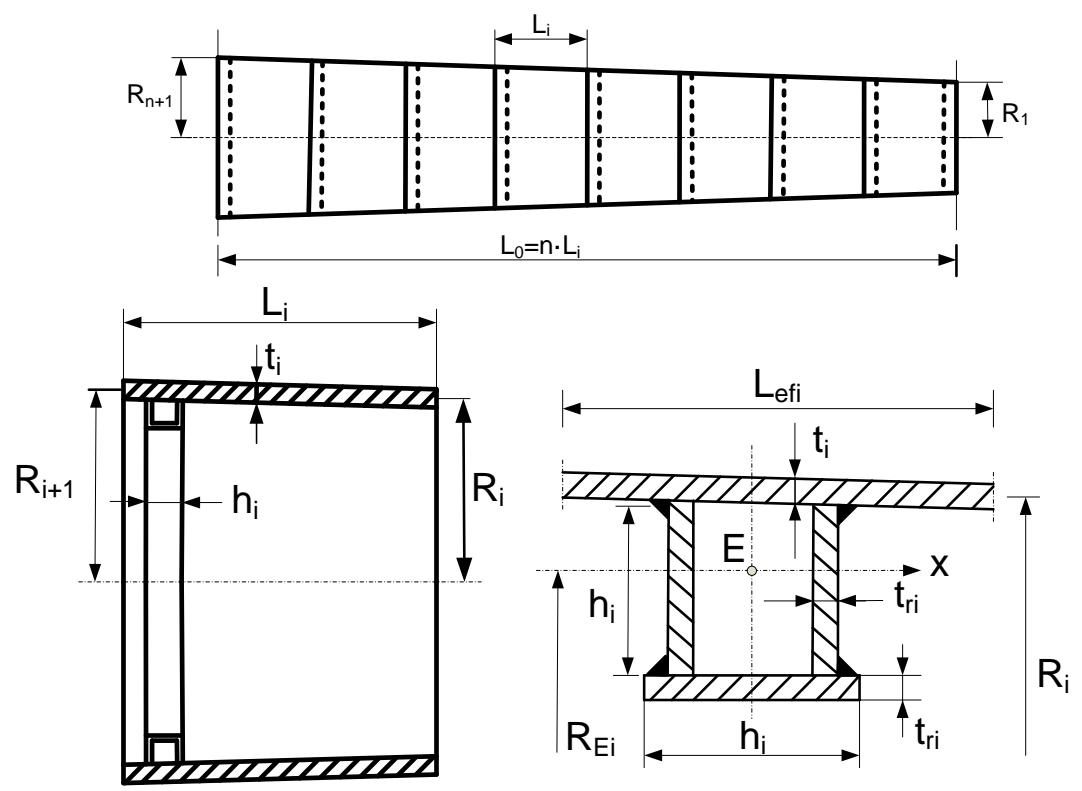

Figure 7. A ring-stiffened slightly conical shell with equidistant stiffening. Ring stiffener of welded box section

are as follows:

- Material: steels, Al-alloys, fiber-reinforced plastics.

- Geometry: slightly conical (transition parts between two circular shells), strongly conical (storage tank roofs), truncated.

- Stiffening: ring-stiffeners, stringers, combined, equidistant, non-equidistant. 
- Stiffener profile: flat, box, $T$-, $L$-, $Z$-shape,

- Loads: external pressure, axial compression, torsion, combined.

- Fabrication technology: welding, riveting, bolting, gluing.

In the present study we select the following structural characteristics: steel, slightly conical shell, ring stiffeners of welded square box section to avoid tripping, equidistant and non-equidistant stiffening, external pressure, welding. Design rules of Det Norske Veritas 5,12 are applied for shell and stiffener buckling constraints.

In the case of equidistant stiffening the variables to be optimized are as follows: number of shell segments (n) (Figure 7), shell thicknesses $\left(t_{i}\right)$, dimensions of ringstiffeners $\left(h_{i}, t_{r i}\right)$. The number of stiffeners is $\mathrm{n}+1$, since stiffeners should be used at the ends of the shell, thus, two stiffeners are used in the first shell segment.

In the case of non-equidistant stiffening 13 the variables to be optimized are as follows: length of shell segments for a given shell thickness (Figure 1), dimensions of ring-stiffeners $\left(h_{i}, t_{r i}\right)$. The ring stiffeners are placed at a small distance from the circumferential welds connecting two segments to allow the inspection of welds: this is marked in Figure 1 by dotted lines.

The optimization process for the equidistant stiffening has the following parts:

(a) design of thicknesses for each shell segment given by two radii $\left(R_{i}\right.$ and $\left.R_{i+1}\right)$ using the shell buckling constraint,

(b) design of ring stiffeners for each shell segment using the stiffener buckling constraint,

(c) cost calculation for each shell segment and for the whole shell structure.

These design steps should be carried out for a series of segment numbers. On the basis of calculated costs the optimum solution corresponding to the minimum cost can be determined.

The optimization process for the non-equidistant stiffening has the following parts:

(d) design of each shell segment length for a given shell thickness using the shell buckling constraint,

(e) design of ring stiffeners for each shell segment using the stiffener buckling constraint,

(a) cost calculation for each shell segment and for the whole shell structure.

These design steps should be carried out for a series of shell thicknesses. On the basis of calculated costs the optimum solution corresponding to the minimum cost can be determined.

Numerical data (Figure 7) : Total shell length $L=15000 \mathrm{~mm}$, side radii $R_{\text {min }}=$ $R_{1}=1850$ and $R_{\max }=R_{n+1}=2850 \mathrm{~mm}$, yield stress of steel $f_{y}=355 \mathrm{MPa}$, with a safety factor for yield stress $f_{y 1}=f_{y} / 1.1$, external pressure intensity $p=0.5 \mathrm{MPa}$, safety factor for loading $y_{b}=1.5$, Poisson ratio $\nu=0.3$, elastic modulus $E=2.1 \times 10^{5}$ MPa.

Results of the optimization for equidistant stiffening: The detailed calculations are carried out for numbers of shell segments $n=3-15$. The corresponding material and total costs are summarized in Table 7. 
Table 7. The material and total costs in $\$$ for investigated numbers

of shell segments. The optima are marked by bold letters

\begin{tabular}{|ccccccccc|}
\hline$n$ & 3 & 4 & 5 & 6 & 8 & 10 & 12 & 15 \\
\hline$K_{m}$ & 48,540 & 43,540 & 40,350 & 36,830 & 33,390 & 31,390 & $\mathbf{2 9 , 8 4 0}$ & 31,192 \\
$K$ & 85,390 & 82,360 & 81,430 & $\mathbf{7 9 , 2 1 0}$ & 80,260 & 82,120 & 84,811 & 95,818 \\
\hline
\end{tabular}

It can be seen that the optimum number of shell segments for material cost is $n_{\text {Mopt }}=12$ and for total cost $n_{\text {opt }}=6$. This difference is caused by the fact that the fabrication (assembly, welding and painting) cost represents a large amount of total cost. The cost data show that forming the plate elements into shell shape, welding and painting make up a significant part of the fabrication cost.

In order to characterize the dimensions of the optimum structure, the main data are given in Table 8 .

Table 8. Main dimensions (in $\mathrm{mm}$ ) of the optimum shell structure

\begin{tabular}{|ccccc|}
\hline$i$ & $R_{i}$ & $t_{i}$ & $h_{i}$ & $t_{r i}$ \\
\hline 1 & 1850 & 18 & 121 & 4 \\
2 & 2017 & 19 & 132 & 4 \\
3 & 2184 & 20 & 143 & 5 \\
4 & 2351 & 20 & 156 & 5 \\
5 & 2518 & 21 & 155 & 5 \\
6 & 2685 & 22 & 153 & 5 \\
7 & 2852 & 23 & 152 & 6 \\
\hline
\end{tabular}

Results of the optimization for non-equidistant stiffening: The detailed calculations are carried out for shell thicknesses $t_{i}=14-20 \mathrm{~mm}$. The corresponding material and total costs are summarized in Table 9 .

Table 9. The material and total costs in $\$$ for investigated shell thicknesses. The optima are marked in bold letters

\begin{tabular}{|ccc|}
\hline$t_{i}$ & $K_{m}$ & $K$ \\
\hline 14 & $\mathbf{2 8 , 4 9 0}$ & 82,280 \\
16 & 29,620 & 76,150 \\
18 & 32,390 & $\mathbf{7 5 , 0 4 0}$ \\
20 & 38,170 & 80,120 \\
\hline
\end{tabular}

It can be seen that the optimum shell thickness for material cost is 14 and for total cost $18 \mathrm{~mm}$. This difference is caused by the fact that the fabrication (assembly, welding and painting) cost represents a large amount of total cost. The cost data show that forming the plate elements into shell shape, welding and painting make up a significant part of the fabrication cost.

In order to characterize the dimensions of the optimum structure, the main data are given in Table 10 . 
Table 10. Main dimensions (in $\mathrm{mm}$ ) of the optimum shell structure $(t=18 \mathrm{~mm})$

\begin{tabular}{|cccc|}
\hline$R_{i}$ & $L_{i}$ & $h_{i}$ & $t_{r i}$ \\
\hline 1850 & 2630 & 121 & 4 \\
2025 & 2376 & 134 & 4 \\
2183 & 2189 & 146 & 5 \\
2329 & 2044 & 158 & 5 \\
2465 & 1927 & 170 & 5 \\
2593 & 1831 & 182 & 6 \\
2715 & 1750 & 194 & 6 \\
2832 & $(1680)$ & 207 & 7 \\
\hline
\end{tabular}

Comparison of the two structural versions (Tables 9 and 10 shows that the nonequidistant stiffening produces more economic solution than that of the equidistant one: material costs 28,490 vs $29,340 \$$ and total costs 75,040 vs $79,210 \$$.

\section{A Simply SUPPORTED SECTORIAL Plate With DIFFERENT STIFFENINGS SUBJECT TO UNIFORMLY DISTRIBUTED NORMAL LOAD}

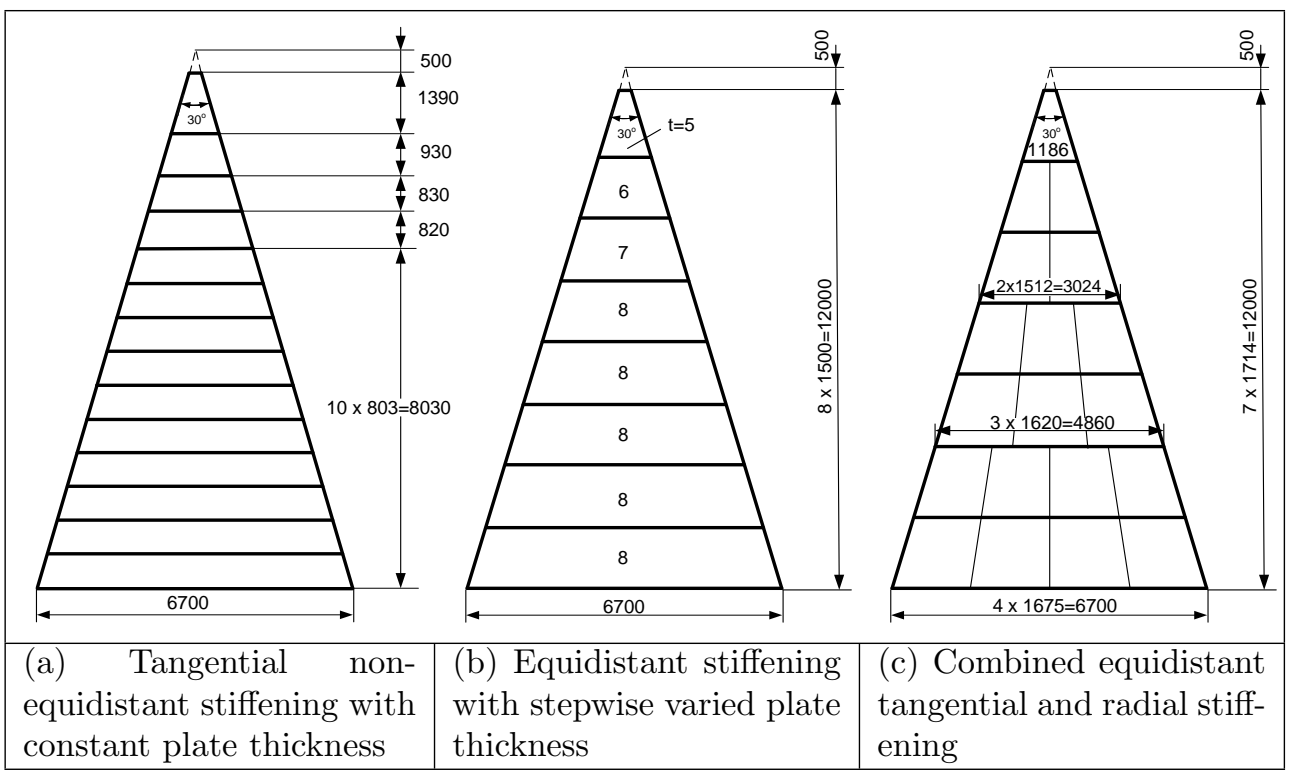

Figure 8. Stiffened sectorial plates

Halved rolled I-section stiffeners are used [14. Comparing the costs of the different structural solutions, it can be concluded that in the present numerical problem the lowest total cost corresponds to equidistant tangential stiffening with variable base plate thickness $(n=8, K=6,320 \$)$. 
A similarly low total cost can be achieved by non-equidistant tangential stiffening with constant base plate thickness $(t=4 \mathrm{~mm}, K=6,437 \$)$.

Equidistant tangential stiffening combined with radial stiffeners needs much higher total cost $(t=6, K=7,730 \$)$.

The lowest mass (or material cost) corresponds to non-equidistant tangential stiffening with constant base plate thickness $\left(t=4 \mathrm{~mm}, K_{m}=2,094 \$\right)$ followed by combined stiffening $\left(t=4 \mathrm{~mm}, K_{m}=2,456 \$\right)$. The solution giving the lowest total cost needs larger material cost $\left(n=8, K_{m}=3,077 \$\right)$. These data show that the fabrication costs (welding and painting cost) significantly affect the total cost.

The comparison with the cost of the unstiffened sectorial plate shows that the stiffened version is much more economic than the unstiffened one.

\section{Conclusions}

The developed cost calculation method makes it possible to select the most economic structural version. Cost comparison is presented in the case of four welded steel structural types. The compared versions are optimized for minimum cost with the same conditions (loads, constraints, some main dimensions, cost calculation method).

In the case of a cantilever column loaded by compression and bending with a constraint on top sway, the square box section constructed from cellular plates is the most economic version.

A square plate supported at four corners subject to a uniform normal load can be constructed as an orthogonally stiffened plate or a cellular plate with nearly the same cost. The cellular plate is competitive to the plate stiffened on one side because of its high torsional stiffness.

The comparison of two versions of a wind turbine tower shows that the cost of a tubular truss structure is much lower than that of the slightly conical circular shell, because the tubular truss version has much lower mass and surface.

In the case of a slightly conical ring-stiffened shell subject to external pressure the non-equidistant stiffening is more economic than the equidistant one, since the shell thicknesses influence the cost significantly. For the investigated stiffened sectorial plates the lowest total cost corresponds to equidistant tangential stiffening with variable base plate thickness.

\section{REFERENCES}

1. FARkAs, J. and JÁRmai, K.: Analysis and Optimum Design of Metal Structures. Balkema, Rotterdam, Brookfield, 1997.

2. JÁrmai, K. and FARKaS, J.: Cost calculation and optimization of welded steel structures. Journal of Constructional Steel Research, 50, (1999), 115-135.

3. FARKas, J. and JÁRmai, K.: Economic Design of Metal Structures. Millpress, Rotterdam, 2003. 
4. Farkas, J. and JÁrmai, K.: Design and Optimization of Metal Structures. Horwood Publishing, Chichester, UK, 2008.

5. Det Norske Veritas (DNV): Buckling strength analysis. Classification Notes No. 30. 1. Høvik, Norway. 1985.

6. Farkas, J., JÁrmai, K., and Snyman, J. A.: Global minimum cost design of a welded square stiffened plate supported at four corners. In 7th World Congress on Structural and Multidisciplinary Optimization, Paper AO381. Seoul, Korea, 2007. Abstract p. 84. CD ROM.

7. FARKAS, J. and JÁrmai, K.: Optimum design and cost comparison of a welded plate stiffened on one side and a cellular plate both loaded by uniaxial compression. Welding in the World, 50(3-4), (2006), 45-51.

8. Sales program. Commercial sections. Arcelor Mittal. Long Carbon Europe. 2007.

9. American Petroleum Institute (API): Bulletin 2U. Bulletin on stability design of cylindrical shells. 2nd ed. Washington,. 2000.

10. Eurocode 1. Part 2-4. Wind loads. ENV 1991-2-4. 1999.

11. FARKAs, J. and JÁrmai, K.: Cost comparison of a tubular truss and a ring-stiffened shell structure for a wind turbine tower. In J. A. Packer and S. Willibald (eds.), Tubular Structures XI. Proc. 11th Int. Symposium and IIW Int. Conf. on Tubular Structures, Québec City, Canada, Taylor \& Francis, London, 2006, pp. 341-349.

12. Det Norske Veritas: Buckling strength of shells. Recommended Practice DNV-RP-C202. Høvik, Norway, 2002. 1999.

13. FARKAS, J. and JÁRmai, K.: Minimum cost design of a conical shell - external pressure, non-equidistant stiffening. In R. O. et al. (ed.), Eurosteel 2008 5th European Conference on Steel and Composite Structures Graz Austria. Proceedings, Brussels, ECCS European Convention for Constructional Steelwork, Vol.B., 2008, pp. 1539-1544.

14. Farkas, J. and JÁrmai, K.: Minimum cost design of a welded stiffened steel sectorial plate. Steel Construction, 2(2), (2009), 131-137.

15. FARKAS, J. and JÁrmai, K.: Optimum design of a welded stringer-stiffened steel cylindrical shell subject to axial compression and bending. Welding in the World, 49(5-6), (2005), 115-135.

16. FArkas, J. and JÁrmai, K.: Minimum cost design of a square box column composed from orthogonally stiffened welded steel plates. In J. Farkas and K. Jármai (eds.), Design, Fabrication and Economy of Welded Structures. Int. Conf. Proc., Chichester, UK, Horwood Publishing, 2008, Miskolc, Hungary, pp. 61-70. 